\title{
Cura espiritual, biomedicina e intermedicalidade no Santo Daime
}

\author{
Spiritual healing, biomedicine and intermedicality \\ in Santo Daime
}

Isabel Santana de Rose'

\begin{abstract}
RESUMO: Este trabalho toma como ponto de partida a descrição do sistema de cuidados da saúde da comunidade do Santo Daime Céu da Mantiqueira, localizada no sul do estado de Minas Gerais. Este sistema de cuidados da saúde é caracterizado por uma pluralidade de práticas terapêuticas provenientes de diferentes campos; pela presença de um numero expressivo de profissionais da área da saúde; e pela incorporação de recursos biomédicos. Procuro aqui compreender a estreita imbricação entre essas diferentes práticas e paradigmas terapêuticos a partir do conceito de intermedicalidade, desenvolvido no âmbito dos estudos sobre saúde indígena, visando dar conta de contextos caracterizados pela convivência de sistemas médicos distintos. Com base no estudo de caso sobre o Céu da Mantiqueira, argumento que as fronteiras entre espiritualidade e terapia, entre os usos rituais/religiosos e os usos terapêuticos da ayahuasca, entre ciência e religião são porosas e difusas, se interpenetram e se misturam. .
\end{abstract}

Palavras-chave: Santo Daime; espiritualidade; terapia; intermedicalidade; recursos biomédicos.
ABSTRACT: Céu da Mantiqueira is a Santo Daime community located in the south of Minas Gerais state, Brazil. This text is based in the description of this community's health care system. This health care system is characterized by a diversity of therapeutic practices from different fields, by the presence of an expressive number of health care professionals, and by the incorporation of biomedical resources. Grounded in the concept of intermedicality, I highlight the interconnections between the many therapeutic practices and paradigms present in this Santo Daime center. This concept was developed in Indigenous health studies and is directed to examine contexts characterized by the coexistence of different medical systems. Further, based on the case study of Céu da Mantiqueira, I argue that the boundaries between spirituality and therapy, between the ritual/ religious and the therapeutic uses of ayahuasca, and between science and religion are spread out, diffuse and blurred.

Keywords: Santo Daime; spirituality; therapy; intermedicality; biomedical resources.

\footnotetext{
1. Doutora em Antropologia Social pela Universidade Federal de Santa Catarina (UFSC), com uma tese que trata da formação de redes xamânicas contemporâneas no Brasil a partir de um estudo de caso realizado na aldeia guarani Yynn Morothi Wherá (Biguaçu, SC) (Rose, 2010). Minhas principais áreas de interesse incluem antropologia da saúde, antropologia da religião, xamanismo e saberes e fazeres tradicionais. Sou coautora do livro Religiões ayahuasqueiras: um balanço bibliográfico (Labate; Rose; Santos, 2008) e autora de uma série de artigos e capítulos publicados em periódicos e livros nacionais e internacionais. Atualmente sou professora visitante no Programa de Pós-Craduação em Antropologia Social da Universidade Federal de Alagoas (PPCAS/UFAL).
} 


\section{Introdução: Santo Daime e a expansão das religiões ayahuasqueiras brasileiras}

Inicio este texto com uma introdução sobre as religiões ayahuasqueiras, especialmente o Santo Daime. Abordo também alguns dos desdobramentos contemporâneos do processo de expansão e internacionalização dessas religiões, especificamente os debates legais nacionais e internacionais relacionados ao consumo da ayahuasca fora dos contextos indígenas. Na segunda parte do texto descrevo o sistema de cuidados da saúde, as principais práticas terapêuticas e as concepções de saúde, doença e cura presentes no Céu da Mantiqueira, comunidade daimista localizada no sul do estado de Minas Cerais. A seguir, introduzo o conceito de intermedicalidade, desenvolvido na área da antropologia da saúde, principalmente em estudos ligados com o campo da saúde indígena, e voltado para pensar contextos caracterizados pela convivência de sistemas médicos distintos (Greene, 1998; Follér, 2004). Finalmente, sugiro empregar este conceito para analisar o sistema de cuidados da saúde do Céu da Mantiqueira, ressaltando especialmente a incorporação de recursos biomédicos e a presença de profissionais da área da saúde, bem como a interpenetração dinâmica entre diversos sistemas médicos presente nesta comunidade.

As religiões ayahuasqueiras brasileiras, Santo Daime, União do Vegetal (UDV) ${ }^{2}$ e Barquinha ${ }^{3}$, emergiram no norte do país, nos estados do Acre e Rondônia, entre as décadas de 1930 e 1960, tendo começado como pequenos cultos carismáticos baseados nas experiências místicas e visionárias de seus fundadores. A mais conhecida entre essas religiões, o Santo Daime, foi fundada no Acre pelo negro maranhense Raimundo Irineu Serra (1872-1971), conhecido como Mestre Irineu. O primeiro grupo criado por ele nos anos 1930 começou como uma congregação com características comunitárias, sendo formado principalmente por caboclos e imigrantes nordestinos, pobres e com pouco acesso à educação formal. O grupo foi formalmente estabelecido em 1945 e em 19630 Mestre Irineu criou o Centro de Iluminação Cristã Luz Universal, CICLU-Alto Santo, que representou o primeiro esforço para a institucionalização dessa religião4.

Uma versão anterior deste texto foi publicada na coletânea Ayahuasca y Salud (Rose, 2013). Agradeço a Beatriz Labate e José Carlos Bouso, os organizadores da coletânea, e a Josep M. Fericgla, o editor, pela autorização para publicar esta tradução. A pesquisa de campo no Céu da Mantiqueira foi realizada entre 2000 e 2002, ao longo de diversas estadias com durações variadas. Agradeço a todos os dirigentes e participantes dessa comunidade e especialmente à Madrinha Udi, que tive o grande prazer de reencontrar recentemente.

2 O Centro Espírita Beneficente União do Vegetal, também chamado de União do Vegetal ou simplesmente UDV foi criado pelo baiano José Gabriel da Costa, conhecido como Mestre Gabriel, em 1961 no estado de Rondônia. Esse sistema religioso é caracterizado pelas influências cristãs, kardecistas e ameríndias e por uma organização altamente hierárquica, centralizada e burocrática. Atualmente a UDV tem pelo menos 20 mil membros e constitui a maior entre as religiões ayahuasqueiras brasileiras. Este grupo tem centros em todo o Brasil, assim como nos Estados Unidos, na Austrália e em diversos países europeus (para mais informações, ver, entre outros, Brissac, 1999; Melo, 2010).

A Barquinha foi fundada na cidade de Rio Branco em 1945 pelo maranhense Daniel Pereira de Mattos, conhecido como Frei Daniel. O grupo foi oficialmente registrado como Centro Espírita e Culto de Oração Casa de Jesus Fonte de Luz em 1959. Esta é a numericamente menor, a menos estudada e a menos expansionista entre as religiões ayahuasqueiras. Trata-se de um sistema religioso extremamente plural e complexo, caracterizado pela presença expressiva de práticas mediúnicas, de elementos das religiões afro-brasileiras e pela vida ritual extremamente intensa (para mais informações, ver, entre outros, Araújo, 1999; Mercante, 2012).
} 
Esta religião tornou-se popular principalmente devido ao fato de ser caracterizada pelo consumo ritual da ayahuasca, uma bebida amazônica amarga amplamente conhecida pelas suas propriedades psicoativas e visionárias. Ao longo das últimas três décadas, seu uso tem se expandido para fora da Amazônia, para populações urbanas nas mais diferentes partes do globo. Embora atualmente a ayahuasca seja vista como uma espécie de substância pan-xamânica e no imaginário ocidental seja frequentemente associada a ideias como "medicina tradicional" e "espiritualidade", na verdade é difícil encaixar esta substância em uma definição homogênea. Em parte isto se deve ao fato de que a "ayahuasca" é composta de práticas culturais e religiosas muito diversas, que incluem os sistemas xamânicos indígenas, as religiões ayahuasqueiras, grupos neo-xamânicos e ligados ao movimento da Nova Era, e centros turistas e terapêuticos (Labate et al., 2017, p. 1). Somado a isto, a ayahuasca pode ser composta de diferentes plantas, tem muitos nomes e sua ingestão pode ocasionar diferentes tipos de experiências e visões, dependendo do contexto. No âmbito do Santo Daime, esta bebida é denominada como daime e é vista como um "ser divino" ou como uma espécie de "medicina universal", dotada de agência e capaz de curar e transmitir conhecimento".

O Santo Daime engloba duas linhas ou vertentes principais: diversos grupos que se autoidentificam como "Alto Santo" e um outro conjunto que ficou popularmente conhecido como "linha do Padrinho Sebastião". Enquanto o Alto Santo permaneceu praticamente restrito ao estado do Acre, a linha do Padrinho Sebastião foi a principal responsável pela expansão nacional e internacional dessa religião. Esta vertente foi fundada por Sebastião Mota de Melo (1920-1990) em 1974 e é representada pela Igreja do Culto Eclético da Fluente Luz Universal Patrono Sebastião Mota de Melo ou ICEFLU. Sua sede nacional encontra-se localizada no Céu do Mapiá, centro fundado em 1983 e situado no interior do estado do Amazonas. ${ }^{6}$

Inicialmente o ICEFLU era composto por cerca de quarenta famílias que viviam num regime comunitário, e até os anos 1970 este grupo permaneceu praticamente restrito à região amazônica. A partir dos anos 1980 esta vertente começou a se expandir para fora da Amazônia, sendo que centros ligados a este grupo são atualmente encontrados em todas as principais cidades brasileiras. Somado a isto, na década de 1990 esta organização também se difundiu para o exterior. Atualmente podem ser encontrados grupos associados ao ICEFLU em pelo menos 43 países, sendo que apenas na Europa existem cerca de 40 centros do Santo Daime (Assis; Labate, 2014) 7 . Esse processo de expansão e internacionalização gerou profundas transformações nessa religião, incluindo aspectos como sua composição social e demográfica, bem como seu simbolismo, cosmologia, práticas e dinâmicas (ver, entre outros, Assis e Labate, 2014; Labate et al., 2017).

\footnotetext{
5 A denominação "daime" indica uma invocação ao espírito da bebida, a quem as pessoas pedem (por isso dai-me) luz, saúde, iluminação, e assim por diante (Groisman, 1999).

6 Uma diferença importante entre o Alto Santo e o ICEFLU é que este grupo, desde seu início, tinha características ecléticas e plurais, que se refletiram na sua abertura para a inserção dinâmica de novos componentes ritualísticos e para a incorporação de elementos de outras religiões na sua cosmologia e práticas religiosas. Por outro lado, os centros ligados ao Alto Santo são em geral menos permeáveis às inovações e mudanças. 7 Para mais informações sobre o processo de expansão e internacionalização do Santo Daime, ver, entre outros, Assis e Labate (2014); Labate et al. (2017); Labate et al. (2018). Para uma revisão da literatura sobre o tema, ver Labate, Rose e Santos (2008).
} 
Um dos desdobramentos da expansão do Santo Daime e da UDV é sua inserção nas dinâmicas do campo religioso contemporâneo mais amplo, bem como em debates nacionais e internacionais ligados a temas como políticas sobre drogas, liberdade religiosa, patrimonialização e direitos humanos (Assis; Labate, 2014). As disputas legais envolvendo o uso da ayahuasca fora dos contextos indígenas estão associadas à presença do DMT, o princípio psicoativo central da bebida, que é proibido pela Convenção de Substâncias Psicotrópicas da ONU de 1971. Nesse contexto, essas religiões têm desempenhado um papel chave em debates científicos e jurídicos nacionais e internacionais.

No Brasil essas discussões começaram nos anos 1980, e as religiões ayahuasqueiras desempenharam um papel central no processo de obter um status legal para esta substância. Depois de anos de debates, o Conselho Nacional de Políticas sobre Drogas (CONAD) regulamentou a ayahuasca como sendo legal para os usos definidos como rituais e religiosos em 1985, com base no princípio da liberdade religiosa, tendo reafirmado esta decisão em 2010. Apesar de representar um avanço importante no contexto das políticas proibicionistas vigentes no Brasil e no mundo, esta decisão traz uma série de ambiguidades, entre as quais, como veremos adiante, se destaca a dificuldade de definir as fronteiras entre os usos da ayahuasca definidos como "rituais" e "religiosos" e seus usos "terapêuticos" (Rose, 2005).

OSanto Daime e a União do Vegetal (UDV) vêm atravessando muitos conflitos legais também no exterior. Estes conflitos começaram nos anos 1990, paralelamente à internacionalização desses grupos. Um exemplo importante é a batalha da UDV pela permissão para consumir ayahuasca nos Estados Unidos. Depois de uma longa disputa que também girou em torno do princípio de liberdade religiosa, em 2006 a Suprema Corte norte-americana garantiu aos membros da UDV o direito de consumir esta bebida durante suas cerimônias religiosas em todo o território dos Estados Unidos. Este caso envolveu muitos pesquisadores de diferentes áreas e especialistas jurídicos e contribuiu para criar bases e precedentes importantes relacionados aos debates internacionais sobre os usos rituais e religiosos da ayahuasca ${ }^{8}$.

Como mencionado anteriormente, no Brasil o uso religioso da ayahuasca se encontra atualmente em uma situação legal e conta com uma legitimidade relativamente estável, embora o mesmo não possa ser dito com relação aos usos terapêuticos dessa bebida, que seguem gerando polêmica. Neste sentido, a resolução do CONAD de 2010 reforça a proibição anterior de empregar a ayahuasca com fins terapêuticos, embora incentive a realização de pesquisas científicas sobre este tema (CONAD, 2010). Nesta resolução, "terapia" é definida como "atividade ou processo destinado à cura, manutenção ou desenvolvimento da saúde que leve em conta princípios éticos científicos". Isto significa que não incluídos os usos terapêuticos no âmbito dos "trabalhos de cura nos quais se faz uso da ayahuasca inseridos dentro do contexto da fé" (CONAD, 2010, p. 7); ou seja, dentro dos contextos considerados religiosos. Por outro lado, as práticas conduzidas fora dos rituais tidos como estritamente religiosos não são consideradas legítimas, sendo vedadas "até que se comprove uma eficiência por meio das investigações científicas realizadas por centros de pesquisa vinculados a instituições acadêmicas, obedecendo a metodologias científicas". Esta 
resolução afirma ainda que "o reconhecimento da legitimidade do uso terapêutico da ayahuasca só se dará após a conclusão de pesquisas que a comprovem" (CONAD 2010, p. 7).

Os usos da ayahuasca definidos como "terapêuticos" devem ser pensados no contexto do processo de expansão e internacionalização das religiões ayahuasqueiras, e da consequente diversificação e multiplicação das formas de consumo desta bebida. Enquanto inicialmente essas religiões foram compostas principalmente por caboclos e imigrantes, pobres e com pouco acesso à educação formal, atualmente elas atraem sobretudo pessoas provenientes das classes médias ealtas urbanas, escolarizadas e influenciadas pelos valores e práticas que fazem parte do movimento da Nova Era. Consequentemente, temas como cura, autoconhecimento, desenvolvimento sustentável, xamanismo e culturas tradicionais passaram a fazer parte dos hinos e da cosmologia daimista. Somado a isto, as associações ocidentais comuns entre a ayahuasca, o xamanismo, a natureza e a floresta amazônica, cura e experiências espirituais também contribuíram para colocar esta bebida nas rotas internacionais do turismo xamânico e psicodélico, atraindo o interesse de um público em busca de estados alterados de consciência, terapias alternativas, povos distantes e natureza exótica.

Enquanto, como vimos, grande parte das discussões legais sobre o uso da ayahuasca fora dos contextos indígenas, tanto no Brasil quanto no exterior, girou em torno do princípio da liberdade religiosa, na prática não é simples delimitar as fronteiras entre o ritual/religioso e o científico, pois estas dimensões se interpenetram e se misturam de diferentes maneiras, gerando novas e interessantes sínteses.

A seguir, partindo de uma análise do sistema de cuidados da saúde do Céu da Mantiqueira, procuro desenvolver esta ideia, argumentando que esta comunidade é caracterizada por um continuum espiritual-terapêutico.

\section{O Céu da Mantiqueira e seu sistema de cuidados da saúde}

O Céu da Mantiqueira é uma comunidade do Santo Daime filiada ao ICEFLU e localizada no sul do estado de Minas Gerais, perto da cidade de Camanducaia. Esta comunidade foi fundada em 1998, ainda que funcionasse informalmente desde1993. Aolongo da trajetória do Céu da Mantiqueira, diversos acontecimentos apontam para a construção e reconstrução de uma identidade coletiva como um "centro de cura", sendo que esta identidade se sustenta na história do grupo. Na época da minha pesquisa de campo, realizada entre 2000 e 2002, vários participantes desta comunidade me contaram que, quando foram iniciados os trabalhos espirituais com o Santo Daime lá, os guias e mentores espirituais se manifestaram através dos médiuns que estavam presentes e disseram que aquele era um centro de cura. A temática da cura tem, portanto, importância fundamental para este grupo, constituindo um dos eixos que contribui para construir sua identidade e sua especificidade.

Da perspectiva daimista, se considera que todos os rituais do Santo Daime têm potencial de cura. Existem, entretanto, alguns rituais ou "trabalhos" que são direcionados especificamente para a 
cura. No Céu da Mantiqueira, são realizados mensalmente dois desses rituais: o Trabalho de Cura e o Trabalho de Mesa Branca, ambos considerados muito importantes pelos participantes da comunidade.

A realização frequente desses rituais contribui para construir e legitimar a identidade da comunidade como um centro de cura. São também esses os ritos que costumam atrair pessoas de outros grupos, em geral membros de outras igrejas daimistas.

O Trabalho de Cura é considerado como um trabalho da "corrente espiritual", durante o qual os participantes buscam contatar o seu "Eu Superior"10 e também os seres espirituais para receber instruções, orientações e curas. Como o próprio nome indica, no Trabalho de Cura a intenção do ritual encontra-se especialmente direcionada para a cura, que pode ser voltada tanto para os participantes da "corrente" quanto para pessoas ausentes".

Já o Trabalho de Mesa Branca se caracteriza pela grande influência do espiritismo kardecista, contando com uma sequência de orações de Allan Kardec. Este trabalho também é chamado de "banca aberta", pois é aberto para a incorporação de espíritos, direcionada para o desenvolvimento da mediunidade dos participantes. O ritual de Mesa Branca se difere do padrão dos outros rituais daimistas. Enquanto de modo geral estes costumam ser caracterizados pela disciplina e pelo comedimento das ações, o ritual de Mesa Branca é marcado por uma relativa flexibilidade e por uma expressão individual mais livre (Labate, 2004b; MacRae, 2000). Os participantes têm maior liberdade de movimento e expressão, visando ao desenvolvimento da mediunidade. Este é incentivado e considerado como parte do processo terapêutico e de autoconhecimento (Labate, 2004b). ${ }^{12}$

Somado a isto, os participantes do Céu da Mantiqueira utilizam uma ampla gama de práticas terapêuticas provenientes de diferentes campos, como do próprio Santo Daime, da biomedicina, de grupos indígenas, de outras religiões e das chamadas terapias alternativas. Um aspecto fundamental é a presença de um número significativo de profissionais da área da saúde neste centro, incluindo terapeutas, fisioterapeutas, enfermeiros, médicos, psiquiatras e psicólogos.

A inserção desses profissionais tem diferentes desdobramentos, tais como um processo de "terapeutização", que se expressa principalmente no desenvolvimento de uma tendência de que as pessoas que participam da comunidade realizem terapia ou outros tipos de tratamento com os profissionais da área da saúde que fazem parte do grupo, como veremos adiante.

Outro processo relevante é a penetração do discurso biomédico/científico nas práticas e nos discursos daimistas. Assim, uma das questões fundamentais levantadas pela inserção dos

9 Os participantes do Santo Daime consideram que, durante os rituais, a união das pessoas forma uma "corrente" de energia. Esta "corrente espiritual" constitui uma espécie de entidade coletiva à qual podem ser atribuídas características como harmonia/desarmonia, força/ fraqueza etc. Neste sentido, é possível pensar na "corrente espiritual" como uma metáfora do próprio grupo (Rose, 2005).

10 De acordo com Alberto Groisman (1999), os membros do Santo Daime concebem a pessoa como sendo composta por três dimensões: o "aparelho", a "matéria" e o "espírito". As categorias "espírito" e "matéria" estariam relacionadas a duas outras categorias: o "Eu Inferior" e o "Eu Superior". O primeiro encontra-se ligado às motivações materiais, o segundo às motivações espirituais, e ambos fazem parte da natureza humana. Nesse sentido, um dos objetivos dos rituais daimistas seria despertar ou revelar o "Eu Superior", ou seja, a natureza espiritual do homem.

11 Para mais informações sobre o Trabalho de Cura, ver, entre outros, Groisman (1999); Groisman e Sell (1996).

12 Para mais informações sobre este ritual, ver Rose (2005). 
profissionais da saúde em uma comunidade religiosa se refere à convivência entre o "paradigma biomédico-científico" e a "cosmologia daimista-espiritual" (Rose, 2005).

Para procurar compreender essas interessantes imbricações, busquei levantar e discutir as principais categorias culturais envolvidas nas experiências de cura, saúde e doença para os participantes do Céu da Mantiqueira, empregando o conceito de "sistema de cuidados da saúde", proposto por Arthur Kleinman (1980). Kleinman sugere que as práticas de cuidado com a saúde, inclusive a biomedicina, sejam vistas como sistemas culturais. Segundo este autor, alguns papéis sociais importantes nos sistemas de cuidados da saúde incluem os terapeutas e os pacientes, que não podem ser compreendidos fora de seus contextos. Ele considera que a doença e a cura também fazem parte dos sistemas de cuidado da saúde e são experiências culturalmente constituídas.

De acordo com Kleinman, as concepções sobre saúde e doença estão sempre ligadas a intervenções terapêuticas específicas, constituindo sistemas de conhecimento e ação. Desta maneira, essas concepções não podem ser entendidas separadamente da maneira como são colocadas em prática. Ele divide o sistema de cuidados da saúde em três setores, que define como "popular" "folk" e "profissional'13. Segundo o autor, em cada um desses settings, a doença é percebida, interpretada e rotulada de determinada maneira, e são aplicadas diferentes formas de cuidados.

A lógica que orienta o sistema de cuidados da saúde do Céu da Mantiqueira e a incorporação de práticas e discursos provenientes de outros contextos neste sistema deve ser compreendida a partir do exame das concepções daimistas de saúde, doença e cura. Na visão de Kleinman, estas concepções são partes integrantes do sistemas de cuidado da saúde. Vamos a seguir examinar estas concepções.

Para os participantes do Santo Daime, a doença encontra-se frequentemente associada a transgressões sociais e espirituais e a desequilíbrios nas relações com o mundo e o cosmos (Groisman, 1999; Groisman e Sell, 1996; Peláez, 1994). A doença pode ser explicada com referência a agentes externos, como maus fluidos ou espíritos, ou ainda a partir de transgressões realizadas em vidas passadas. Também costuma ser considerada como uma oportunidade para realizar um "trabalho interior" para descobrir suas causas. Nesse sentido, a doença constitui uma manifestação do mundo espiritual. Alberto Groisman e Ari Sell (1996) afirmam que os daimistas veem a doença como um evento complexo e contextual, no qual os aspectos sociais e simbólicos são fundamentais.

A saúde é vista como o oposto da doença e é encarada como um estado ideal de harmonia e equilíbrio. Nesse sentido, mais do que estados estáticos, saúde e doença constituem processos. Enquanto a doença é compreendida como a manifestação da desarmonia ou do desequilíbrio, a saúde está relacionada à presença de harmonia e equilíbrio em vários planos (Rose, 2005). Deste modo, as explicações sobre a causalidade das doenças costumam abranger dimensões que não são enfatizadas pela biomedicina.

\footnotetext{
13 Esther Jean Langdon (comunicação pessoal, 2005) propõe que estes termos podem ser traduzidos respectivamente como "familiar", "popular" e "profissional". De acordo com Kleinman (1978), o primeiro desses setores envolve principalmente a família, mas também inclui a rede social e a comunidade. Langdon destaca o papel central do setor popular, que é formado pelos especialistas em saúde não profissionais. Já o setor profissional é constituído pela biomedicina e pelas outras tradições médicas e de cura que são profissionalizadas (Kleinmam, 1978, p. 87).
} 
De acordo com Groisman e Sell (1996), o paradigma terapêutico dominante no Santo Daime não é alopático, ou seja, não está centrado na remissão dos sintomas físicos. Dessa maneira, a remissão dos sintomas não constitui necessariamente um indicador concreto da cura, da mesma maneira que a morte de uma pessoa não significa que ela não tenha sido curada (Peláez, 1994).

Segundo Groisman e Sell (1996), os elementos centrais da cultura daimista não podem ser considerados isoladamente, pois atuam conjuntamente no campo simbólico, criando uma situação favorável para que as pessoas reavaliem seus hábitos e comportamentos e reflitam sobre suas vidas e experiências. Portanto, o conceito daimista de cura deve ser considerado como sendo mais complexo do que um mero evento orgânico, dado que envolve o ser humano como um todo, e inclui tanto as relações com outros seres vivos como relações cósmicas (Groisman; Sell, 1996). Este conceito é mais amplo que a noção biomédica de cura; faz referência também a outras dimensões que vão além do corpo físico ${ }^{14}$, colocando uma grande ênfase na dimensão espiritual ${ }^{15}$. A cura pode se processar em diferentes níveis: pode se referir a um aumento no entendimento ou na compreensão; a um insight; a uma mudança de comportamento e/ou de consciência; à resolução de um problema familiar ou financeiro, e assim por diante. A noção de cura, porém, é equacionada principalmente com a de equilíbrio: equilíbrio no corpo, entre as dimensões materiais e espirituais, entre a pessoa e suas relações, e entre o ser humano e o cosmos (Rose, 2005). Deste modo, a cura é compreendida fundamentalmente como uma "cura espiritual", enquanto o Santo Daime pode ser visto como um meio ou caminho para obtê-la (Peláez, 1994).

Agora que examinamos estas concepções, vamos passar para as principais práticas terapêuticas utilizadas pelos participantes do Céu da Mantiqueira. Estas podem ser divididas em dois grupos: as práticas do primeiro grupo estão mais relacionadas ao que chamei de "polo da espiritualidade", enquanto as do segundo estão ligadas ao "polo da terapia" (Rose, 2005). No polo da terapia encontram-se práticas como a psicoterapia, psicoterapia com daime eo uso de medicamentos alopáticos, que serão discutidas com mais detalhe adiante. Já no polo da espiritualidade, além dos rituais daimistas, já mencionados, existem práticas como:

- Tinturas feitas de plantas e flores: podem ser empregadas durante os rituais, sendo aspergidas pelo recinto; ou individualmente, passadas no corpo em pequenas quantidades. Sua utilização tem como base as propriedades das plantas que as compõem. Por exemplo, existem plantas consideradas estimulantes, como o alecrim; calmantes, com a menta; ou ainda de "limpeza", como o manjericão" mental", associado ao raciocínio, lógica e pensamentos; e o "corpo espiritual", ligado à alma e que representa a conexão com a dimensão espiritual. 15 Para as pessoas ligadas ao Santo Daime, a realidade é formada pela interação entre duas dimensões: o "mundo material" e o "mundo espiritual". A primeira diz respeito aos fenômenos empíricos da vida cotidiana, o mundo visível; já a segunda encontra-se relacionada principalmente ao mundo implícito ou invisível. De acordo com Groisman (1999), mais do que dois mundos separados ou distintos, a existência dessas duas dimensões corresponde a duas formas de perceber o todo. 
- Florais da Amazônia: trata-se de um sistema de essências florais confeccionadas a partir de plantas nativas e cultivadas e desenvolvido por mulheres daimistas residentes no Céu do Mapiá. Essas essências florais atuariam nos "corpos sutis", possibilitando o reequilíbrio das energias e uma evolução da consciência. ${ }^{17}$

- Kambô: é um dos nomes do sapo Phyllomedusa bicolor, cuja secreção é empregada pelos povos indígenas do Alto Juruá (Acre), tais como Katukina, Kaxinawa, Yaminawa e Ashaninka, principalmente para tirar a "panema"18. Seu uso é reinterpretado nos meios urbanos, sendo bastante difundido em contextos relacionados com os grupos neoayahuasqueiros ou neoxamânicos e com o movimento da Nova Era (ver Lima e Labate, 2007).

Partindo da análise do sistema de cuidados da saúde do Céu da Mantiqueira, procurei construir um modelo que levasse em conta a estreita imbricação entre a espiritualidade e a terapia. Esse modelo está baseado em dois processos simultâneos e complementares.

O primeiro foi definido como terapeutização da espiritualidade e encontra-se ligado à inserção dos profissionais da área da saúde nesse centro e ao desenvolvimento da tendência de que seus membros busquem profissionais da saúde que também sejam ligados ao Santo Daime. Assim, a noção de "terapia", categoria presente nos discursos característicos tanto da biomedicina quanto das terapias alternativas, torna-se um valor entre os participantes do Céu da Mantiqueira. O segundo processo foi definido como espiritualização das práticas terapêuticas. Neste processo, a categoria "espiritualidade", valor fundamental tanto na cosmologia daimista como no contexto mais amplo dos grupos e práticas ligados ao movimento da Nova Era, passa a ser uma parte importante do discurso e das práticas terapêuticas dos profissionais da saúde que fazem parte do Céu da Mantiqueira.

Desta maneira, no processo de terapeutização da espiritualidade os valores característicos da biomedicina e das práticas chamadas alternativas interagem com os valores característicos da cosmologia daimista e os influenciam.

Ao mesmo tempo, no processo de espiritualização da terapia os valores e categorias constitutivos do Santo Daime influenciam as práticas terapêuticas dos profissionais da saúde que fazem parte do Céu da Mantiqueira, contribuindo para que essas práticas sejam adaptadas e modificadas. Isto aponta para a presença de um continuum espiritual-terapêutico no qual a espiritualidade e a terapia não podem ser pensadas como dimensões separadas (Rose, 2005).

denso e sintético. A limpeza pode acontecer em um nível individual ou grupal, e pode referir-se à dimensão material, à dimensão espiritual ou a ambas. Este conceito costuma ser associado às catarses fisiológicas que podem ser experimentadas durante os rituais (vômitos, diarreias etc.) (Peláez, 1994). A limpeza tem uma conotação positiva, pois se considera que é através dela que é possível ter acesso ao conhecimento e às curas propiciadas pela ingestão do daime.

17 Para uma apresentação sobre os florais da Amazônia escrita pelas responsáveis pelo seu desenvolvimento, ver Freire e Barsé (2000).

18 De acordo com Galvão e DaMatta (1955 e 1973, citados em Lima e Labate, 2007), no panorama amazônico a panema é entendida como incapacidade, principalmente para a caça. Edilene Lima e Beatriz Labate mostram como no contexto da transposição do uso do kambô para os meios urbanos, o significado da panema é reinterpretado. De acordo com essas autoras, no circuito terapêutico do movimento da Nova Era, o kambô é entendido ao mesmo tempo como "remédio da ciência" e "remédio da alma"; ou seja, por um lado são valorizadas suas propriedades bioquímicas, por outro, suas origens indígenas. 
Esta dupla imbricação entre espiritualidade e terapia encontra-se presente também em um contexto mais amplo, principalmente no movimento chamado Nova Era ou nova consciência religiosa ${ }^{19}$. Nesse contexto, a categoria de "espiritualidade terapêutica" assume um lugar central (Amaral, 2000). Esta categoria também adquire um papel importante no âmbito dos diferentes grupos nos quais o uso da ayahuasca é definido como terapêutico. Em todos esses casos, as fronteiras entre espiritualidade e terapia, entre o uso ritual/religioso e o uso terapêutico da ayahuasca, entre ciência e religião são porosas e difusas; se interpenetram e se misturam. Os diferentes tipos de discursos e práticas presentes - espiritual, terapêutico, religioso e científico - não são contraditórios ou excludentes; podem ser ativados separadamente ou ao mesmo tempo, dependendo dos interlocutores e do contexto.

\section{Intermedicalidade}

Na minha dissertação de mestrado (Rose, 2005) procurei analisar o sistema de cuidados da saúde do Céu da Mantiqueira como um sistema plural, como sugerido por Kleinman (1980), devido à variedade de opções terapêuticas existentes. Aqui proponho repensar esta ideia de pluralidade médica a partir do conceito de intermedicalidade. Este conceito foi desenvolvido na antropologia da saúde, principalmente em estudos ligados ao campo da saúde indígena, e procura levar em conta contextos caracterizados pela convivência de sistemas médicos distintos, originando sistemas médicos híbridos (Greene, 1998; Follér, 2004). Diferente da noção de pluralidade médica, o conceito de intermedicalidade faz parte de um enfoque que procura ver a realidade social como sendo constituída por negociações entre dois ou mais sujeitos politicamente ativos, destacando que estes são dotados de agência social (Greene, 1998; Follér, 2004).

Este conceito foi proposto inicialmente por Shane Greene (1998), autor que realiza uma análise crítica do desenvolvimento médico nos países do chamado terceiro mundo, buscando mostrar como a compreensão que a biomedicina tem das etnomedicinas está fundamentada em uma visão ocidental que opõe progresso e estática cultural. Assim, a "medicina tradicional" é vista como um fenômeno estático e passivo, enquanto a "medicina moderna" é pensada como ativa e dinâmica. Esta concepção traz como consequência a ideia de que a biomedicina e a ciência são hierarquicamente superiores e são agentes de uma mudança que ativa (através da cientifização) uma etnomedicina que de outra maneira estaria estagnada (e seria necessariamente "não científica"). Greene sugere que esta linguagem reflete uma compreensão limitada e envolve uma série de construções ocidentais que apagam a agência dos praticantes das etnomedicinas e dos povos

19 Esse movimento, bastante heterogêneo e denominado de diferentes formas, é caracterizado pela intersecção entre novas formas de espiritualidade e de religiosidade, práticas terapêuticas alternativas e vivência de experiências ecléticas pelas classes medias urbanas; ou ainda a emergência de uma "nova cultura espiritual". Esse fenômeno está ligado à constituição de projetos e estilos de vida mais amplos no contexto das metrópoles e se relaciona com aspectos que caracterizam o panorama da religiosidade contemporânea (ver, entre outros, Magnani, 1999; Maluf, 2005). 
indígenas. Tomando como referência esta discussão, ele propõe o conceito de intermedicalidade, que pretende levar em conta "um espaço conceitualizado de medicinas híbridas e agentes socialmedicalmente conscientes" (1998, p. 641, tradução minha).

Com base neste conceito, este autor faz uma análise do xamanismo aguaruna contemporâneo, referindo-se a uma sessão xamânica específica transcrita por ele. Greene chama atenção especialmente para a presença de elementos da biomedicina ocidental nesta sessão, que ele define como "híbrida" (1998, p. 649). Segundo o autor, as referências constantes às injeções e aos medicamentos alopáticos mostram que os Aguaruna têm a biomedicina em alta conta.

Eles conferem à biomedicina um papel culturalmente importante, e isso aponta para a forma como os medicamentos alopáticos, as injeções e o xamanismo encontram-se imbricados na prática de uma "etnomedicina híbridizada" (1998, p. 650). Creene mostra que os recursos biomédicos tornam-se xamanizados no discurso dos Aguaruna. Estes se apropriam do poder da biomedicina, canalizando-o para seu próprio repertório xamânico. Dessa maneira, a xamanização dos recursos biomédicos torna-se uma maneira de "empoderar" a técnica xamânica.

Opontocentral do argumento deGreene équeas apropriações xamânicas dos procedimentos biomédicos precisam ser compreendidas contextualmente. Em sua análise, ele mostra como essas apropriações contribuem para fortalecer tanto o sistema xamânico quanto a feitiçaria entre os Aguaruna. Desse modo, a presença de elementos biomédicos na prática xamânica aguaruna não ameaça esse sistema xamânico; pelo contrário, a sessão descrita por Greene indica que uma etnomedicina híbrida pode contribuir para o fortalecimento e a valorização do xamanismo.

Outra autora que emprega o conceito de intermedicalidade é May-Lis Follér (2004). Ela propõe investigar uma "zona de contato" ${ }^{20}$ onde a biomedicina e o conhecimento tradicional indígena interagem tanto na prática quanto na teoria (2004, p. 129). Como Greene, Follér chama atenção para o fato de que a atividade biomédica participa do projeto colonial. Ela propõe, portanto, tratar de uma estrutura histórica e cultural específica: o discurso colonial.

Somado a isto, esta autora destaca que, tanto nas publicações antropológicas como nos projetos governamentais, a cultura indígena costuma ser descrita como sendo estática. Assim, de acordo com ela, os conhecimentos indígenas "são considerados menos valiosos que o conhecimento científico, e tidos como um obstáculo ao desenvolvimento" (2004, p. 131). Follér aponta que os europeus muitas vezes são vistos "como ativadores de uma etnomedicina destituída de sua própria agência" (Alberte Ramos, 2000, apud Follér 2004, p. 132) e critica esta visão, afirmando que "os povos indígenas estão longe da passividade: ao contrário, possuem agência social" (Follér, 2004, p. 133).

Para Follér, a biomedicina continua sendo uma forma proeminente de conhecimentos médicos e de ideologia, não somente devido a sua eficácia curativa, mas também como resultado da expansão da economia global de mercado. Assim, a "aceitação entusiasmada da biomedicina por parte dos povos indígenas" (2004, pp.134-135) não pode ser explicada apenas a partir de argumentos

20 De acordo com Follér, "zona de contato" é um conceito elaborado por Mary Louise Pratt e se refere ao "espaço dos encontros coloniais, o espaço no qual os povos antes separados pela geografia e pela história entram em contato e estabelecem relações contínuas, sendo que estas que geralmente envolvem condições de coação, desigualdade radical e conflito intratável" (Pratt 1992, apud Follér, 2004, p. 123). 
como eficácia terapêutica ou tecnologia superior. Também devem ser levados em conta fatores ideológicos e ecológicos. Uma ideia fundamental em sua abordagem é a de que "o conhecimento biomédico é construído em um contexto cultural, especificamente o europeu, e está embutido na tradição cultural ocidental" (2004, p. 135).

Esta autora afirma que atualmente a biomedicina ocidental é parte importante da realidade Shipibo-Conibo, e propõe reinterpretar essa zona de contato usando o conceito de intermedicalidade como ferramenta analítica. Segundo Follér, "produtos biomédicos, tais como medicamentos, muitas vezes são usados em novos contextos ou em tradições culturais que não as europeias" (2004, p. 136). No caso dos Shipibo-Conibo, graças a uma "simultaneidade de tradições epistemológicas diferentes, os povos indígenas incorporam artefatos e ideias de terras longínquas, exercendo trabalho social e construindo algo novo" (2004, p. 136). Follér ressalta a simultaneidade no encontro entre esses artefatos derivados de discursos médicos distintos e na forma como eles são colocados em prática.

Aautora define o caso dos Shipibo-Conibo como uma "mistura de fronteiras epistemológicas" e cita outros casos semelhantes, nos quais acontece o que ela chama de "indigenização da biomedicina" (Follér, 2004, p. 137). De acordo com ela, esses exemplos revelam um espaço em que pessoas vindas de regiões diferentes criam uma zona de contato na qual a interação desses atores sociais distintos resulta na criação de algo novo. Para Follér, nesses espaços "há um fluxo de conhecimento entre os discursos biomédicos e etnomédicos. A intermedicalidade significa que há um laço entre pelo menos dois discursos de conhecimento. O espaço intermédico é o novo discurso construído entre as tradições médicas anteriores" (2004, p. 143).

Follér afirma ainda que os encontros entre diferentes sistemas médicos mostram que a intermedicalidade constrói novas formas de hibridismo. Para ela, isso significa queas fronteiras entre as epistemologias da biomedicina e das medicinas indígenas têm se misturado. O que esta autora procura mostrar, portanto, é que os conhecimentos indígenas são dinâmicos, criativos e sujeitos a influências, e que a negociação e renegociação entre as diferentes formas de conhecimento médico se dá constantemente. Desta maneira, "as fronteiras entre diferentes formas de conhecimentos médicos são fluidas e produzem ativamente um espaço de intermedicalidade" (Follér, 2004, p. 145). Ela destaca ainda que este espaço não é homogêneo; pelo contrário, "a medicina híbrida é um processo variável, contínuo e dinâmico" (p. 145).

\section{Intermedicalidade no Céu da Mantiqueira}

O conceito de intermedicalidade é muito interessante para pensar o sistema de cuidados de saúde do Céu da Mantiqueira devido à interpenetração simultânea de vários sistemas médicos distintos que existe nesta comunidade. Pretendo, então, a partir das reflexões de Greene e Follér, retomar a discussão sobre este sistema de cuidados da saúde, pensando especialmente sobre a convivência entre o paradigma característico do discurso e das práticas biomédicas-científicas e o paradigma característico do discurso e das práticas daimistas-espirituais. Minha proposta é que, 
como ressaltam Greene e Follér, o sistema de cuidados da saúde do Céu da Mantiqueira deve ser visto como sendo ativo.

O que quero mostrar é que, também no caso do Céu da Mantiqueira, o uso de práticas terapêuticas de diferentes origens e, principalmente, a valorização dos recursos biomédicos precisam ser compreendidos contextualmente, conforme sugere Greene. Além disso, considero que aqui também é possível pensar numa "mistura de fronteiras epistemológicas" (Follér, 2004, p. 137): por um lado, o discurso e as práticas biomédicas são reinterpretados e adaptados a um novo contexto no qual a dimensão da espiritualidade tem um lugar central; por outro, há uma penetração do discurso biomédico no discurso daimista sobre a cura.

Vou partirde uma análise mais detalhada de como os profissionais da área da saúde queestão inseridos no Céu da Mantiqueira influenciam o sistema de cuidados da saúde desta comunidade, ao mesmo tempo que são influenciados por ele. Para tanto, vou me referir especificamente à valorização da terapia e ao uso dos medicamentos alopáticos no contexto do Céu da Mantiqueira.

Como vimos, um dos desdobramentos relevantes da inserção dos profissionais da área da saúde neste centro é o desenvolvimento de uma tendência das pessoas da comunidade a se tratarem com participantes do mesmo grupo, principalmente a fazerem terapia com os psicólogos e psiquiatras. De acordo com relatos, entrevistas e observações de campo, o que distingue este tipo de terapia é a possibilidade de levar em conta também aspectos espirituais, que seriam ignorados por grande parte dos profissionais da saúde e que, para os daimistas, representam uma dimensão fundamental da vida. Este é um dos principais fatores do processo de terapeutização da espiritualidade ao qual me referi anteriormente.

Neste processo, a noção de terapia passa a ser um valor importante para os participantes do Céu da Mantiqueira. Neste contexto, porém, essa categoria é ressignificada e reinterpretada a partir da cosmologia daimista. O que é valorizado é a combinação da terapia com as práticas e rituais daimistas. Considera-se que, por um lado, o daime tem a capacidade de catalisar o processo terapêutico, aprofundando e acelerando seus resultado ${ }^{21}$ e que, por outro, a terapia (realizada com alguém que também está ligado ao Santo Daime) pode ajudar a lidar com as intensas experiências que costumam ser vivenciadas durante os rituais, auxiliando no desenvolvimento espiritual. Neste sentido, o fato de participar do Santo Daime influencia de maneira decisiva a vida pessoal e profissional dos médicos e terapeutas ligados ao Céu da Mantiqueira, sendo que a dimensão da espiritualidade adquire um lugar central nas suas práticas e discursos.

Um exemplo disso é uma proposta ao mesmo tempo interessante e polêmica que estava sendo desenvolvida por alguns profissionais da área da saúde ligados ao Céu da Mantiqueira no período da minha pesquisa de campo: trata-se de um trabalho experimental de psicoterapia com daime. Este trabalho, chamado de cura xamânica e definido como um ritual, consistia em uma sessão especial, realizada dentro de um processo terapêutico mais amplo, durante a qual era utilizado

21 Esta concepção parece ser, de fato, muito frequente: aparece também no trabalho de Labate (2004) e em comunicações pessoais de vários profissionais da saúde com os quais pude ter contato fora do âmbito da pesquisa realizada no Céu da Mantiqueira e que utilizam a ayahuasca para fins terapêuticos. 
o daime ${ }^{22}$. De acordo com um dos profissionais que desenvolveu esta experiência, durante essa sessão, a ampliação de consciência proporcionada pela bebida seria direcionada para pontos nos quais o paciente tinha dificuldades, sendo que tanto os terapeutas quanto o paciente tomavam o daime. Este caso da terapia com daime pode ser pensado como um desdobramento da ênfase na combinação entre daime e terapia, que passam então a ser não apenas recursos paralelos, mas que também podem ser acionados simultaneamente.

A utilização da categoria "ritual" para definir esta experiência e a combinação de elementos do Santo Daime com elementos provenientes das terapias alternativas e da biomedicina apontam mais uma vez para a interpenetração entre o espiritual e o terapêutico, reforçando a ideia do continuum entre estas dimensões.

A disseminação da terapia entre os participantes do Céu da Mantiqueira era acompanhada por um amplo uso dos medicamentos alopáticos. Os profissionais da área da saúde que participam da comunidade não viam o uso de medicação alopática e a ingestão do daime como antagônicos; pelo contrário, a ideia de que, dependendo do caso, esta medicação é necessária e mesmo indispensável era bastante recorrente. Todos os profissionais da área da saúde que eu entrevistei afirmaram que atendiam tanto participantes do Santo Daime quanto pessoas que não fazem parte desta religião, e todos afirmaram também que percebiam grandes diferenças entre os processos terapêuticos desses dois tipos de pacientes. Com relação à questão do uso da medicação alopática, e especificamente de medicamentos psiquiátricos, uma das psiquiatras que eu entrevistei afirmou que notava diferenças entre os pacientes que ela medicava que tomavam daime e os que não tomavam. De acordo com ela, muitas vezes os que não tomavam o daime não conseguiam mais ficar sem a medicação, enquanto os ligados ao Santo Daime precisavam da medicação apenas por um período para ajudar em momentos difíceis, conseguindo prosseguir depois sem necessitar dela. Assim, da mesma maneira que as práticas terapêuticas ligadas ao "polo da espiritualidade" abordadas mais no início do texto, procedimentos como a terapia, a terapia com daime e o uso da medicação alopática podem ser acionados como ferramentas auxiliares na cura e mesmo no desenvolvimento espiritual, sendo utilizados a partir de uma lógica característica do sistema de cuidados da saúde do Céu da Mantiqueira.

Proponho que a valorização de elementos como a terapia e os medicamentos alopáticos neste contexto seja pensada a partir da noção de intermedicalidade. Nesse caso, não acontece uma assimilação passiva dos recursos biomédicos; pelo contrário, estes são ativamente reinterpretados a partir da cosmologia daimista. Retomando a ideia do continuum espiritual-terapêutico, podemos pensar que neste contexto há uma influência decisiva dos valores daimistas na lógica segundo a

Infelizmente não pude presenciar nenhuma dessas sessões. De acordo com os profissionais da área da saúde que estavam conduzindo esta experiência, no espaço onde as seções aconteciam havia um altar com imagens das principais lideranças daimistas, além de objetos que costumam estar presentes nos ritos realizados nas igrejas (velas, incensos etc.). Também eram usados outros elementos característicos do Santo Daime, tais como orações e hinos. Paralelamente, podiam ser empregadas técnicas provenientes da psicologia, da psiquiatria e mesmo do campo das chamadas terapias alternativas, como a terapia de vidas passadas e a respiração holotrópica, por exemplo (para mais informações, ver Rose, 2005 e 2006. Para outros exemplos de psicoterapia com daime, ver Labate, 2004). 
qual as práticas terapêuticas vindas de outros campos são incorporadas ao sistema de cuidados da saúde do Céu da Mantiqueira.

Existem, entretanto, alguns outros aspectos importantes que devem ser levados em conta se quisermos compreender a valorização dos profissionais da área da saúde e dos recursos biomédicos no contexto do Céu da Mantiqueira.

Um primeiro fator é que a presença desses profissionais e recursos agrega um caráter "científico" às concepções e práticas daimistas. Por um lado, isto contribui para conferir a essas concepções e práticas uma legitimidade que advém da valorização da biomedicina na sociedade ocidental contemporânea. Por outro, a ênfase que esta sociedade coloca no que Kleinman (1980) chama de "setor profissional" do sistema de cuidados da saúde pode ter uma influência na posição que os médicos e terapeutas têm dentro de uma comunidade que procura construir uma identidade como um centro de cura.

Nesse sentido, observei que no Céu da Mantiqueira os profissionais da área da saúde tinham um status importante, tendo o papel de a) diagnosticar as pessoas que não podiam tomar daime ${ }^{23}$; b) orientar os participantes dos rituais sobre a compatibilidade entre medicamentos e a bebida $^{24}$; c) observar os participantes dos rituais, podendo conversar com eles quando achavam que havia necessidade e; d) receitar medicação alopática ou outros tipos de tratamento. Estes dados indicam que estas pessoas detinham posições de poder dentro da comunidade e apontam para a possibilidade de que, em muitos casos, eles poderiam ter também funções de controle.

Outro aspecto importante está ligado a um tema pouco abordado e que diz respeito aos possíveis problemas advindos do consumo da ayahuasca. De fato, não são raros os casos de pessoas que passam por problemas ou dificuldades, que podem ser em diferentes graus e poderiam de alguma maneira estar relacionadas ao consumo da bebida.

Em termos nativos, a perda do controle da experiência com o daime é chamada de "rodar", sendo que as pessoas "rodadas" frequentemente são aquelas que têm dificuldades para lidar com as experiências vivenciadas sob o efeito da bebida, as quais muitas vezes podem ser intensas ${ }^{25}$. Assim, a valorização dos profissionais da saúde e dos recursos biomédicos, como os medicamentos, também pode estar relacionada à necessidade de lidar com uma essa questão, polêmica e pouco discutida na literatura sobre o tema.

Finalmente, por um lado, o fato desses profissionais contemplarem a dimensão espiritual na terapia, adotando uma espécie de "retórica da espiritualidade", pode ser pensado também como uma estratégia adaptativa frente a um mercado terapêutico que passou a valorizar cada vez mais

23 Segundo os profissionais da área da saúde ligadas ao Céu da Mantiqueira com os quais eu conversei, existem alguns casos nos quais não é indicado tomar daime: trata-se de pessoas diagnosticadas como psicóticas, esquizofrênicas ou que estejam tomando medicação com base na fluoxetina. Neste centro, para evitar que as pessoas tomem daime sem ter a devida orientação, era realizada uma entrevista e uma anamnese com as pessoas que participavam do ritual pela primeira vez (Rose, 2005).

24 Segundo os psiquiatras que entrevistei, a princípio os únicos medicamentos incompatíveis com o daime são os inibidores de recaptação de serotonina com base na fluoxetina. De acordo com eles, outros tipos de medicamentos podem ser usados sem problemas (Rose, 2005). 
esta dimensão. Entretanto, por outro lado, o discurso biomédico e científico adquire importância na medida em que pode ser usado como uma estratégia no contexto de busca de legitimidade e legalidade para as práticas das religiões e grupos ayahuasqueiros.

Existem, então, dois discursos distintos que podem ser acionados para se referir ao daime. O primeiro é o "daimista-espiritual", no qual, como vimos, esta bebida é vista como um ser divino e como medicina universal; o outro é o "biomédico-científico", que parte de um ponto de vista muito mais farmacológico e explica a eficácia do daime com referência às suas propriedades físicoquímicas e à maneira como a bebida age no organismo. 0 mais interessante é que não parece haver contradição entre essas lógicas e discursos, que podem ser acionados separada ou simultaneamente, dependendo do contexto. Assim, nas sobreposições dinâmicas entre esses discursos, através das contínuas negociações entre os diferentes paradigmas envolvidos, são geradas novas sínteses.

\section{Reflexões finais}

No Céu da Mantiqueira há, portanto, um encontro entre sistemas médicos diferentes, marcados por paradigmas distintos. Convergem aqui o paradigma espiritual, que caracteriza a cosmologia daimista, e o paradigma científico, ligado à biomedicina. Neste encontro todos os atores envolvidos devem ser considerados como sendo dotados de agência. Assim, enquanto, por um lado, as práticas e os discursos biomédicos passam a ser considerados importantes e a fazer parte do discurso daimista sobre a cura, por outro lado, os profissionais da área da saúde que participam desta comunidade também incorporam o que pode ser chamado de "idioma da espiritualidade" em suas práticas e discursos.

Procurei ressaltar que no sistema de cuidados da saúde do Céu da Mantiqueira as práticas provenientes da biomedicina e dos outros cam pos são ativamente reinterpretadas. Sua incorporação, portanto, deve ser compreendida contextualmente. No lugar de enfraquecer as concepções e práticas daimistas relacionadas à cura, à saúde e à doença, a presença dos profissionais da área da saúde e de elementos como a terapia e os medicamentos alopáticos contribui para reforçá-las.

Este encontro de diferentes sistemas médico-religiosos e paradigmas gera um sistema no qual acontece uma mistura de fronteiras epistemológicas (Follér, 2004, p.137). Há, assim, uma sobreposição simultânea de conhecimentos, criando um espaço intermédico (Follér, 2004, p. 143). Como destaca Follér (2004), a medicina que surge neste espaço tem características tanto da biomedicina quanto da etnomedicina. O novo conhecimento formado através de negociações e renegociações contínuas passa por transformações constantes. A formação deste espaço intermédico híbrido mostra, mais uma vez, que as fronteiras entre espiritualidade e terapia, entre o uso ritual/religioso e o terapêutico da ayahuasca, entre ciência e religião são porosas e difusas. Todas estas fronteiras são fluidas, e as práticas resultantes são caracterizados por sínteses criativas e dinâmicas.

predisposição prévios. Nestas circunstâncias, o daime poderia servir como um "gatilho" ou desencadeador de um quadro mais grave. Segundo eles, porém, a responsabilidade não pode ser colocada na bebida, pois qualquer outra situação também poderia desencadear o problema (Rose, 2005). 


\section{Referências}

ARAÚJO, Wladimyr Sena. Navegando sobre as ondas do daime. História, cosmologia e ritual da Barquinha. Campinas: Editora da Unicamp, 1999.

AMARAL, Leila. Carnaval da alma: comunidade, essência e sincretismo na Nova Era. Petrópolis: Vozes, 2000.

ASSIS, Glauber L.; LABATE, Beatriz C. Dos igarapés da Amazônia para o outro lado do Atlântico: a expansão e internacionalização do Santo Daime no contexto religioso global. Religião $e$ Sociedade, v. 34, n. 2, pp. 11-35, 2014.

BRISSAC, Sérgio. A estrela do norte iluminando até o sul: uma etnografia da União do Vegetal em um contexto urbano. Dissertação (Mestrado em Antropologia Social) - Universidade Federal do Rio de Janeiro. Rio de Janeiro, 1999.

CONSELHO NACIONAL ANTIDROGAS (CONAD). Resolução n. 1, 25 jan. 2010.

GROISMAN, Alberto. Eu venho da floresta. Um estudo sobre o contexto simbólico do uso do Santo Daime. Florianópolis: Editora da UFSC, 1999.

; SELL, Ari. Healing Power: cultural-neurophenomenological therapy of Santo Daime. Yearbook of Cross-Cultural Medicine and Psychotherapy, v. 4, pp. 279-287, 1996.

GREENE, Shane. The shaman's needle: development, shamanic agency and intermedicality in Aguaruna Lands, Peru. American Ethnologist, v. 25, n. 4, pp. 634-658, 1998.

FOLLÉR, May-Lis. Intermedicalidade: a zona de contato criada por povos indígenas e profissionais de saúde. In: LANCDON, E. J.; CARNELO, Luiza (Orgs.) Saúde dos povos indigenas: reflexões sobre antropologia participativa. Rio de Janeiro: ContraCapa/ABA, 2004.

FREIRE, Maria Alice Campos; BARSÉ, Isabel Facchine. Florais da Amazônia. Porto Alegre: Hércules, 2000.

KLEINMAN, Arthur. Concepts and a model for the comparison of medical systems as cultural systems. Social Science and Medicine, v. 12, pp. 85-93, 1978.

. Patients and healers in the context of culture. Berkeley: University of California Press, 1980.

LABATE, Beatriz C. A reinvenção do uso da ayahuasca nos centros urbanos. Campinas: Mercado de Letras, 2004a.

. A literatura brasileira sobre as religiões ayahuasqueiras. In: LABATE, Beatriz. C.; ARAÚJO, Wladimyr S. (Orgs.). O uso ritual da ayahuasca ( $2^{\mathrm{a}} \mathrm{ed}$.). Campinas: Mercado de Letras/FAPESP, 2004b. ; ARAÚJO, Wladimyr S. (Orgs.). O uso ritual da ayahuasca ( $2^{\mathrm{a}}$ ed.). Campinas: Mercado de Letras/FAPESP, 2004.

; ROSE, Isabel S. de; SANTOS, Rafael G. dos. Religiões ayahuasqueiras: um balanço bibliográfico. Campinas: Mercado de Letras/Fapesp, 2008.

; CAVNAR, Clancy; GEARIN, Alex K. (Orgs.). The world ayahuasca diaspora: reinventions and controversies. Londres/Nova lorque: Routledge, 2017.

; CAVNAR, Clancy; GEARIN, Alex. Introduction. The shifting journey of ayahuasca in diáspora. In: (Orgs.). The world ayahuasca diaspora: reinventions and controversies. Londres/Nova lorque, Routledge, 2017. 
; CAVNAR, Clancy (Orgs.). The expanding world ayahuasca diaspora. Apropriation, integration and legislation. Londres/Nova lorque: Routledge, 2018.

LIMA, Edilene C.; LABATE, Beatriz C. "Remédio da ciência" e "remédio da alma": os usos da secreção do kambô (Phyllomedusa bicolor) nas cidades. Campos. Revista de Antropologia Social, v. 8, n. 1, pp. 71-90, 2007.

MACRAE, Edward. Guiado pela lua. Xamanismo e uso ritual da ayahuasca no culto do Santo Daime. São Paulo: Editora Brasiliense, 1992.

. El Santo Daime y la espiritualidad brasileña. Quito: Ediciones Abya-Yala, 2000.

MAGNANI, José Guilherme C. Mystica urbe. Um estudo antropológico sobre o circuito neo-esotérico na metrópole. São Paulo: Studio Nobel, 1999.

MALUF, Sônia W. Mitos coletivos, narrativas pessoais: cura ritual, trabalho terapêutico e emergência do sujeito nas culturas da "Nova Era". Mana, v. 11, n. 2, pp. 499-528, 2005.

MELO, Rosa. "Beber na fonte": adesão e transformação na União do Vegetal. Tese (Doutorado em Antropologia Social) - Universidade de Brasília. Brasília, 2010.

MERCANTE, Marcelo S. Imagens de cura: ayahuasca, imaginação, saúde e doença na Barquinha. Rio de Janeiro: Fiocruz, 2012.

PELAEZ, Maria Cristina. No mundo se cura tudo. Interpretações sobre a cura espiritual no Santo Daime. Dissertação (Mestrado em Antropologia Social) - Universidade Federal de Santa Catarina. Florianópolis, 1994.

ROSE, Isabel S. de. Espiritualidade, terapia e cura. Um estudo sobre a expressão da experiência no Santo Daime. Dissertação (Mestrado em Antropologia Social) - Universidade Federal de Santa Catarina. Florianópolis, 2005.

Repensando as fronteiras entre espiritualidade e terapia: reflexões sobre a 'cura' no Santo Daime. Campos, Revista de Antropologia Social, v. 7, n. 1, pp. 35-52, 2006.

Tata endy rekoe - Fogo Sagrado: encontros entre os Cuarani, a ayahuasca e o Caminho Vermelho. Tese (Doutorado em Antropologia Social) - Universidade Federal de Santa Catarina. Florianópolis, 2010.

Cura espiritual, biomedicina y intermedicalidad en el Santo Daime. In: LABATE, Beatriz C.; BOUSO, José Carlos (Orgs.). Ayahuasca y salud. Barcelona: La Liebre de Marzo, 2013.

. "Santo Daime" e "União do Vegetal". In: Encyclopedia of Latin American Religions. Springer International Publishing, 2018. 